\title{
Learners' Misconceptions in Periodic Table: An Analysis of Cognitive Skills Development
}

\author{
Pinaki Chowdhury
}

Department of Mathematics, Science and Business Education, Faculty of Humanities, Tshwane University of Technology, South Africa

Received October 24, 2021; Revised December 3, 2021; Accepted December 24, 2021

\section{Cite This Paper in the following Citation Styles}

(a): [1] Pinaki Chowdhury, "Learners' Misconceptions in Periodic Table: An Analysis of Cognitive Skills Development," Universal Journal of Educational Research, Vol. 10, No. 1, pp. 57 - 66, 2022. DOI: 10.13189/ujer.2022.100106.

(b): Pinaki Chowdhury (2022). Learners' Misconceptions in Periodic Table: An Analysis of Cognitive Skills Development. Universal Journal of Educational Research, 10(1), 57 - 66. DOI: 10.13189/ujer.2022.100106.

Copyright $\bigcirc 2022$ by authors, all rights reserved. Authors agree that this article remains permanently open access under the terms of the Creative Commons Attribution License 4.0 International License

\begin{abstract}
Development of Cognitive skills is critical for developing the right conceptual ideas in chemistry. Atomic structure, bonding, and associated properties are taught as parts of high school chemistry courses worldwide. The cumulative build-up of misconceptions about the periodic table is to blame for students' poor performance on atoms and bonding-related topics. This is primarily due to a lack of appropriate cognitive abilities. The periodic table is a fundamental organizing principle in chemistry that high school students are introduced to. The purpose of this study is to determine the commonalities among learners' misconceptions about various aspects of the periodic table in two distinct countries. This study had two objectives. To begin with, it demonstrated if learners from different locations developed the same type of alternate concepts. Second, it aided in discovering the most prevalent alternate conceptions in learners' minds regarding the periodic table. This study enrolled 97 students from India and 78 students from South Africa. The quantitative data for this investigation were gathered using a modified BRI. It is noticed that, despite disparities in their social environments, high school students generally possess similar alternate conceptions that act as a learning barrier at their higher level of learning.
\end{abstract}

Keywords The Periodic Table, High School Student, Alternate Concepts

\section{Introduction}

It is widely accepted that teaching in the twenty-first century is markedly different from the way classrooms were used in the nineteenth century. Scholars place a high premium on assisting students in gaining $21^{\text {st }}$ century abilities [1-3]. Learning and innovative skills, Digital literacy skills, and Life and career skills are three main skills a learner needs to develop to survive in $21^{\text {st }}$ century [3]. A more elaborated approach suggests cognitive skills, self-management skills, cooperation skills, flexibility skills, and innovation skills are essential $21^{\text {st }}$ century learning skills for present day learners [2]. Readers need to accept the fact that there exist multiple components under each of the skill category. This study stresses upon identifying the development of all components of cognitive skills. Hence the author uses the word cognitive skills instead of cognitive skill in this document.

Cognitive skills development is a critical $21^{\text {st }}$ century talent that learners must master [2]. Cognitive skills include the acquisition of abilities like; attention, memory, perception, mobility, processing, logic, and reasoning. Attending to the smallest details, such as why we write $\mathrm{H}_{2} \mathrm{O}$ but not $\mathrm{HO}_{2}$. Recognize that $\mathrm{H}$ is a non-metal that is found in group one of the periodic table. Possessing an accurate sense of the properties of an element and relate it to its positions in the periodic table. These are few cognitive skills critical for gaining an accurate conceptual understanding of chemistry. Mobility, processing ability, and reasoning with suitable logic are other necessary qualities for advanced chemical education. Additionally, it is recognized that the twenty-first century would demand a significantly larger workforce trained in fields relating to science and technology [4]. The purpose of this study is to determine whether the cognitive development of students 
studying science changes by location. Chemistry is a significant science subject taught in high school [5]. As a result, the study focused on high school chemistry.

\subsection{Selection of a Topic under High School Chemistry}

Atomic structure, bonding, and associated properties are taught as part of high school chemistry courses worldwide. Periodic table forms part of almost every high school textbooks on this planet [6]. Even then, most students consider periodic table as a difficult topic [6]. It is well-known; prior information aids in the development of alternative notions [7]. Additionally, it is suggested that the cumulative build-up of misconceptions about the periodic table and its topic areas contributes to students' failure in atoms and bonding-related content areas [8]. The periodic table is one of the fundamental organizing concepts of chemistry that high school students are introduced to [9]. The periodic chart serves as the central model for introducing students to the ideas of atoms, molecules, bonding, and their properties [10]. The periodic table is critical for comprehending the chemical properties of elements and accurately anticipating their structure and properties [6-11]. The periodic table is considered to be a tool for organizing all of chemistry [12]. As such, it is critical to identify learners' alternate beliefs about the periodic table and to recommend an appropriate correction approach.

\subsection{A Link with Prior Study}

Identifying students' misconceptions about the periodic table has previously been reported from a South African school, in which learners' difficulty of identifying periodic table as a resource to identify symbols, structure and properties of atoms of elements was observed [8]. The same study also recognized the lack of information about s, $\mathrm{p}, \mathrm{d}$, and $\mathrm{f}$ blocks amongst local learners. Learners from South Africa also exhibited a low confidence in identifying molecules of elements. The current analysis combined data from the prior study [8] with a new set of data acquired from an Indian school. This was done to ascertain the extent to which learners' misconceptions about the periodic table are shared. While this study is assessing trainees' cognitive abilities, it serves two purposes. To begin with, it demonstrates whether learners from diverse backgrounds acquire equivalent alternate notions in a similar fashion by indicating a similar pattern of cognitive impairment. Secondly, it aids in discovering the most prevalent alternate conceptions in learners' minds when it comes to the periodic table. This, in turn, might serve as a common framework for teaching high school students about the periodic table's core sections.

\section{Methodology}

This study employed a quantitative post-testing procedure. The data were gathered using a standardized tool called the modified bonding representative inventory (modified BRI) [13]. The modified BRI is based on and prepared from bonding representative inventories (BRIs) [14-16]. When administering the test, learners received a copy of the periodic table in addition to the inventory. The modified BRI was administered to a group of grade ten and eleven students from an Indian school. Previously, another group of South African learners had the same treatment. To protect ethical integrity, the location, name of the school, and other identifying information about the participating learners are not provided in this publication. Schools are randomly assigned the designations of school one (S1) and school two (S2). Additionally, the courses are referred to as class one (C1) and class two (C2). The next parts will go into greater information about the study.

\subsection{Aim}

The purpose of this study is to ascertain whether there are any widespread misconceptions about the periodic table contents among learners in two schools conveniently located in two distinct countries.

\subsection{Objectives}

The purpose of this study is to determine whether there are any shared alternate notions in the domain of periodic table contents among high school students from two disparate locations.

\subsection{Sample}

Two randomly chosen schools, one in South Africa and one in India, were used as the population for this study. Grade ten and eleven students studying chemistry as a subject in their separate schools were randomly selected based on their convenience and willingness to administer the test. The sample consisted of 97 students from India and 78 students from South Africa. The sample consisted of 92 students in grade eleven and 83 students in grade ten. Because the study's objective was not to examine learners' performance according to their gender, no gender bifurcation of the sample was performed.

\subsection{Instrument for the Study}

This study made use of a standardized inventory termed the modified BRI [13]. The original testing tool contained thirty-seven questions, eight of which were based on the periodic table. Following administration of the test, all eight items relating to the periodic table were separated and reorganized in order from one to eight, and then included in this study. 


\section{Theoretical Structure for the Study}

Each learner constructs knowledge in his or her own unique and active manner in order to make sense of the world around him or her while interpreting incoming information in terms of pre-existing cognitive structure [17-18]. Learning is a semiotic and semantic mediation process that takes place between the learner, the topic, the subject teacher, and the learning environment [18]. Additionally, learning is not a distinct activity from teaching, as the Old Russian term "obučenie or obuchenie" aptly expresses. As a result, the term "teaching-learning process" is frequently used to emphasize obučenie. Does the student from the first location learn differently than the learner from the second location? The reason for this curiosity is that, while the contents are consistent, the teachers and learning atmosphere vary every location. We are working with students from two distinct countries, each with its own unique set of social, cultural, environmental, and economic conditions. According to the Vygotskian School of thinking, learning is the process of conceptualizing and manipulating content in a given environment [18]. In the case of two distinct countries, the population, culture, and background all vary. As a result, the learning environment of learners is also impacted. Learners are also expected to create various forms of misunderstandings in various environments. In this instance, advocating for a shared topic-specific pedagogic subject understanding will be ineffective. Topic specific pedagogic content knowledge is a tool that aids in the development of cognitive abilities in learners. There must be distinct TSPCK for different regions of the world. The remaining question is whether it is prudent to build a universal TSPCK for classroom teachers.

\subsection{Thesis Statement}

The purpose of this study was to investigate two research questions. They are as follows:

1. Is there any similarity in the alternative concepts used by students from two different countries?

2. If yes, what are the most frequently encountered misconceptions (alternative concepts) among students?

\section{Collecting and Analyzing Data}

Following administration of the modified BRI, learners' performances in the periodic table region were separated from the main response sheet and examined for the purposes of this study. Four groups of students from two separate schools participated. There were two groups of students: those in grade ten and those in grade eleven. In one grade, learners were randomly assigned to $\mathrm{C} 1$ and those in the other grade were assigned to $\mathrm{C} 2$. Two groups were formed by students from class one (C 1) and class two (C 2) at school one (S 1), and another two groups by students from class one (C 1) and class two (C 2) at school two (S 2).

\subsection{Primary Scrutiny of Data}

After all data were loaded to an excel file they were scrutinized for their individual characters. Some of these observations are presented here. Figure one depicts learners' responses to Question one as recorded in an excel file and then transformed to a pie chart displaying the percentage of various responses from learners. As seen below, $70 \%$ of engaged learners answered to response number 6 , while only $11 \%$ responded to response number 1 . The same procedure was repeated with data from all eight items for all four classes, in which the percentages of correct and alternate responses were separated and examined separately.

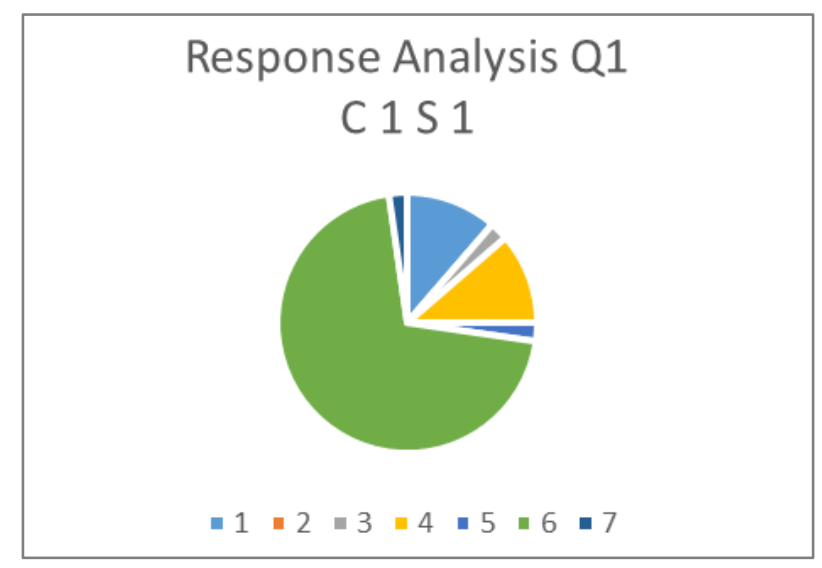

Figure 1. Performance in question 1 by class one of school one

Figure 2 depicts the correct replies for each of the four sample groups using a bar graph. The bar graph depicts the performance of learners enrolled in the same class. The first two bar graphs represent a single class from group designated as $\mathrm{C} 1$. Similarly, the next two bar graphs depict another class from group $\mathrm{C} 2$ from both countries. We can see from this graph that, while school one appears to have fared better than school two, the performance trend does not appear to be constant and regular. 


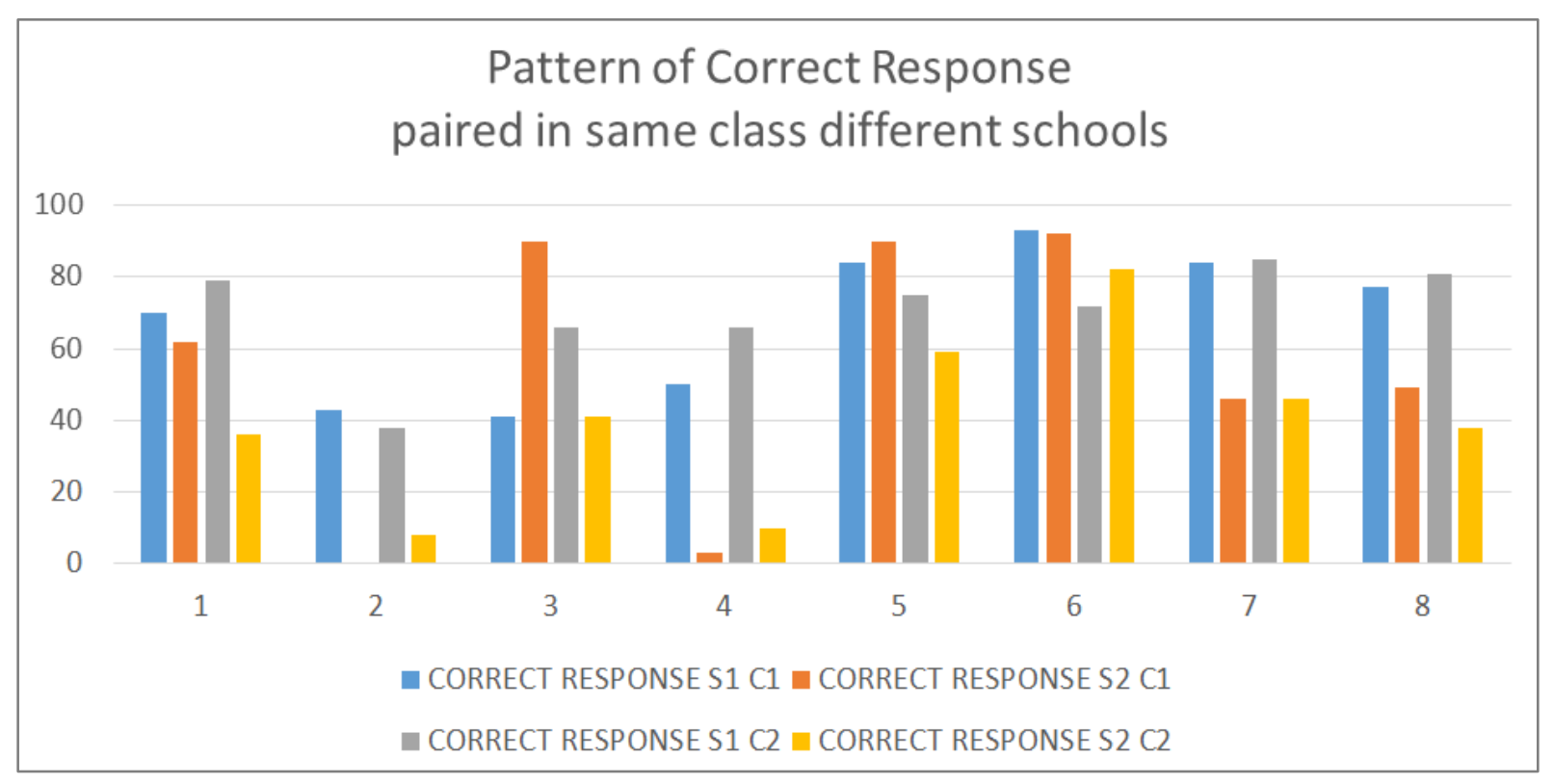

Figure 2. Correct response in $\%$ for both schools by all four sample groups

Table 1. Z score for correct responses for class one and class two

\begin{tabular}{|c|c|c|c|c|c|}
\hline \multirow[t]{3}{*}{ z-Test: } & & & \multicolumn{3}{|c|}{ Two sample for Means: } \\
\hline & \multicolumn{2}{|l|}{ Class 1} & \multicolumn{3}{|c|}{ Class 2} \\
\hline & Variable 1 & Variable 2 & & Variable 1 & Variable 2 \\
\hline Mean & 67.75 & 54 & Mean & 70.25 & 40 \\
\hline Known Variance & 362.4375 & 1213.25 & Known Variance & 188.9375 & 513.25 \\
\hline Observations & 8 & 8 & Observations & 8 & 8 \\
\hline $\begin{array}{l}\text { Hypothesized Mean } \\
\text { Difference }\end{array}$ & 0 & & $\begin{array}{c}\text { Hypothesized Mean } \\
\text { Difference }\end{array}$ & 0 & \\
\hline $\mathrm{z}$ & 0.979744 & & Z & 3.22882 & \\
\hline $\mathrm{P}(\mathrm{Z}<=\mathrm{z})$ one-tail & 0.163606 & & $\mathrm{P}(\mathrm{Z}<=\mathrm{z})$ one-tail & 0.000622 & \\
\hline z Critical one-tail & 1.644854 & & z Critical one-tail & 1.644854 & \\
\hline $\mathrm{P}(\mathrm{Z}<=\mathrm{z})$ two-tail & 1.959964 & & $\mathrm{P}(\mathrm{Z}<=\mathrm{z})$ two-tail & 1.959964 & \\
\hline z Critical two-tail & 1.959964 & & z Critical two-tail & 1.959964 & \\
\hline
\end{tabular}

If there are any statistically significant variations in learners' performance between the two schools, this can be established empirically using a z-score test. To determine $z$-score values, identical classes from two locations were paired together.

It is a well-known fact that if $|z|$ exceeds the $z$-critical value and $p$ is lesser than 0.5 , a statistically significant difference in performance exists between two groups being examined. Z score examination of class one (C1) scores for both locations revealed no statistically significant variation in their performance (Table 1). Class two (C2), on the other hand, demonstrated considerable variations in their performance (Table 1). 

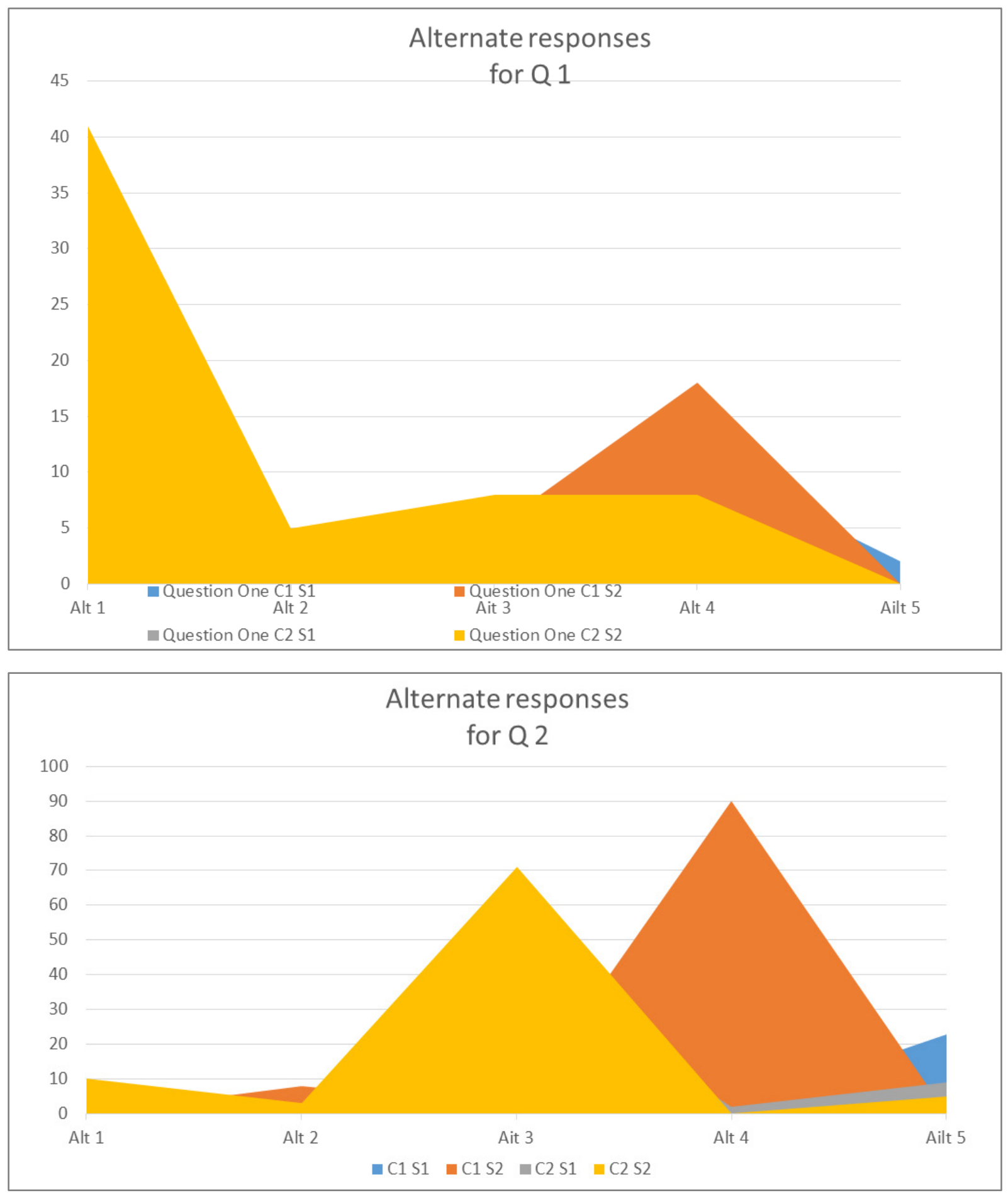

Figure 3. Graphical representation for $\mathrm{Q} 1$ and $\mathrm{Q} 2$ alternate concepts

Figure 3 depicts a few graphs for the alternate responses. All classes from both schools exhibit a similar trend in alternate notions.

\subsection{Analyzing Individual Test Items}

As we observed almost similar trend in alternate notions, it becomes essential for the researcher to scrutinize these trend at individual test item level. At this stage, alternate thoughts for each of the eight items (Question 1 to 8) are arranged and analysed in order (Table 2 to 9). The percentage of correct responses provided by learners is represented by Resp. Cor. in all the tables (Table 2 to 9). C 1 denotes the first class. Likewise, $\mathrm{C} 2$ denotes class two. S 1 and S 2 denote the first and second schools, respectively. Alt 1, Alt 2, and so forth indicate the number of alternative concepts (misconceptions) available to the learners. 
Table 2. Learners' responses in question one

\begin{tabular}{ccccc}
\hline Q 1 & & & & \\
\hline \% Resp. & C1S1 & C1S2 & C2S1 & C2S2 \\
Cor. Resp. & 70 & 62 & 79 & 36 \\
Alt 1 & 11 & 13 & 9 & 41 \\
Alt 2 & 0 & 3 & 0 & 5 \\
Alt 3 & 2 & 5 & 4 & 8 \\
Alt 4 & 11 & 18 & 6 & 8 \\
Alt 5 & 2 & 0 & & \\
\hline
\end{tabular}

Table 2 summarizes all learners' replies to the test's first question. Class two of school two did extremely low on the test (36\%) when compared to all other schools. However, all schools responded most strongly to alternate idea 1 and alternate concept 4 . Alternative idea 3 was responded to by learners from all schools, albeit at a lower rate of response, ranging from $2 \%$ to $8 \%$. It was noticed that the majority of learners linked the periodic table with atomic symbols. The average is around $19 \%$. The periodic table was linked with the structure and symbol of atoms by an average of $11 \%$ of all responding learners. This discovery implies that at least $30 \%$ of all learners are unaware of the relationship between the periodic table and the properties of atoms.

Table 3. Performance analysis in question two

$$
\text { Q } 2
$$

\begin{tabular}{ccccc}
\hline \% Resp. & C1S1 & C1S2 & C2S1 & C2S2 \\
Cor. Resp. & 43 & 0 & 38 & 8 \\
Alt 1 & 2 & 0 & 8 & 10 \\
Alt 2 & 2 & 8 & 2 & 3 \\
Alt 3 & 23 & 2 & 42 & 71 \\
Alt 4 & 2 & 90 & 2 & 0 \\
Alt 5 & 23 & 0 & 9 & 5 \\
\hline
\end{tabular}

An analysis of question 2 suggests that the majority of students in school two (S2) chose the alternate concept 3, indicating that they were unable to connect the atomic number to the structure and properties of atoms (Table 3). In the case of school one, fewer than $50 \%$ of students responded properly. The learners' general dispersed reaction indicates that they struggle with grasping the relationship between; atomic number, atomic structure, and atomic attributes (Table 3).
Table 4. Analysis of test item three

$$
\text { Q } 3
$$

\begin{tabular}{ccccc}
\hline \% Resp. & C1S1 & C1S2 & C2S1 & C2S2 \\
Cor. Resp. & 41 & 90 & 66 & 41 \\
Alt 1 & 9 & 0 & 11 & 28 \\
Alt 2 & 11 & 8 & 2 & 10 \\
Alt 3 & 27 & 2 & 17 & 13 \\
Alt 4 & 9 & 0 & 4 & 8 \\
\hline
\end{tabular}

According to the analysis of test item three (Q 3), approximately $60 \%$ of learners in class one from school one and approximately $60 \%$ of learners in class two from school two lack a firm grasp of the properties of elements and the periodic table (Table 4). These findings indicated that alternative conceptions can easily take precedence in the minds of learners regardless of their class or geography. The most frequently cited alternate notion was number 3 , which implied that group 1 to 12 were primarily composed of metals, but learners overlooked the presence of hydrogen as a non-metal (Table 4). It is noted that the majority of students in class two (C2) in both nations replied to the same substitute notions. These are alternate responses 1 and 3. (Table 4).

Table 5. Analysis of test item four

\section{Q 4}

\begin{tabular}{ccccc}
\hline \% Resp. & C1S1 & C1S2 & C2S1 & C2S2 \\
Cor. Resp. & 50 & 3 & 66 & 10 \\
Alt 1 & 0 & 0 & 8 & 0 \\
Alt 2 & 34 & 79 & 22 & 59 \\
Alt 3 & 9 & 15 & 2 & 26 \\
& & & & \\
Alt 5 & 0 & 3 & 2 & 5 \\
\hline
\end{tabular}

While responding to Question 4, all four groups focused mostly on the alternate notion 2 (Table 5). This observation indicates the absence of a block idea for the periodic table in both countries' learners. Additionally, learners from school two displayed an inability to recognize the periodic table's group and period concepts (alternate concept 3, Table 5). This occurs mostly as a result of superficial memory-based learning. 
Table 6. Response analysis of item five

\begin{tabular}{ccccc}
\hline Q 5 & & & \\
\hline \% Resp. & C1S1 & C1S2 & C2S1 & C2S2 \\
Cor. Resp. & 84 & 90 & 75 & 59 \\
Alt 1 & 6 & 10 & 11 & 31 \\
Alt 2 & 5 & & 9 & 8 \\
Alt 3 & 9 & & 5 & 2 \\
\hline
\end{tabular}

While the majority of learners chose the correct response to test item 5 (Table 6), a significant number chose the other response, revealing their lack of understanding. Learners were unable to recognize that the periodic table's positions correspond to the attributes of elements.

Test item 6 served as a diversion from test item 5 . Test item 5 had four options, however test item 6 had only three. It was interesting to note that class two students from both schools chose option $\mathrm{d}$, a third fictitious alternate solution that was available in question five but not in item six. Additionally, learners desired to select none of the preceding options for item 6 . It is shown as alternate choice 3 because it was not included in the test item 6 at all (Table 7).

Table 7. Analysis of test item six

\section{Q 6}

\begin{tabular}{ccccc}
\hline \% Resp. & C1S1 & C1S2 & C2S1 & C2S2 \\
Cor. Resp. & 93 & 92 & 72 & 82 \\
Alt 1 & 2 & 5 & 8 & 8 \\
Alt 2 & 5 & 3 & 15 & 8 \\
Alt 3 & & 0 & 5 & 2 \\
\hline
\end{tabular}

In the case of item 7 , school one outperformed school two, yet many students from both schools chose the same alternate option 1 and 3 in response to Q 7. (Table 8). Indicates that students are having trouble connecting symbols to elements. Many believed the letters referred to compounds or had nothing to do with elements (Alternate response $1 \& 3$, Table 8 )

Table 8. Response analysis for item seven

Q 7

\begin{tabular}{ccccc}
\hline $\begin{array}{c}\text { \% Resp. } \\
\text { Cor. }\end{array}$ & C1S1 & C1S2 & C2S1 & C2S2 \\
Resp. & 84 & 46 & 85 & 46 \\
Alt 1 & 11 & 21 & 2 & 28 \\
Alt 2 & 0 & 3 & 4 & 15 \\
Alt 3 & 5 & 31 & 9 & 10 \\
\hline
\end{tabular}

When selecting an answer for test item 8 , the majority of students chose alternate response 2. (Table 9). This reflects the reality that learners frequently believe symbols represent compounds.

Table 9. Response analysis for item eight

Q 8

\begin{tabular}{ccccc}
\hline \% Resp. & C1S1 & C1S2 & C2S1 & C2S2 \\
Cor. Resp. & 77 & 49 & 81 & 38 \\
Alt 1 & 2 & 5 & 6 & 8 \\
Alt 2 & 14 & 36 & 9 & 36 \\
Alt 3 & 2 & 5 & 2 & 15 \\
\hline
\end{tabular}

\subsection{Identifying Similarity}

The last stage of data analysis was to determine which alternate responses received the most responses. A weighted average of all alternate responses was calculated. Alternative responses that received a response from $10 \%$ or more of a class's learners were chosen for this reason and were organized in order of 1 to 11 alternate concepts for questions 1 to 8. (Figure 4).

Table 10 has a full overview of each of the prevalent misconceptions. After examining the data acquired during the investigation, the following observations are made.

1. When it came to the atomic number, students from both countries shared similar misconceptions. They lacked trust in their understanding of the atomic number and its relationship to an element's location in the periodic table. Additionally, learners demonstrated their alternative thoughts about the atomic structure and the attributes of atoms in relation to their atomic number.

2. Students in both locations failed to recognize that an element's properties are related to its position in the Periodic Table.

3. Students repeated their confidence in demonstrating the same misconceptions. They continually failed to match the positions of elements in the periodic table with their attributes (alternate concepts 4, 5, 6 in table 10).

4. Learners refused to acknowledge the presence of the s, $\mathrm{p}, \mathrm{d}$, and f blocks in periodic table. Additionally, they demonstrated some ambiguity regarding groupings and time periods.

5. A lack of confidence on the part of learners is also evident in one of the most fundamental aspects of atoms. That is, the usage of alphabetical symbols to represent various elements, elements' molecules, and compounds' molecules. 


\section{Most responded alternate responses}

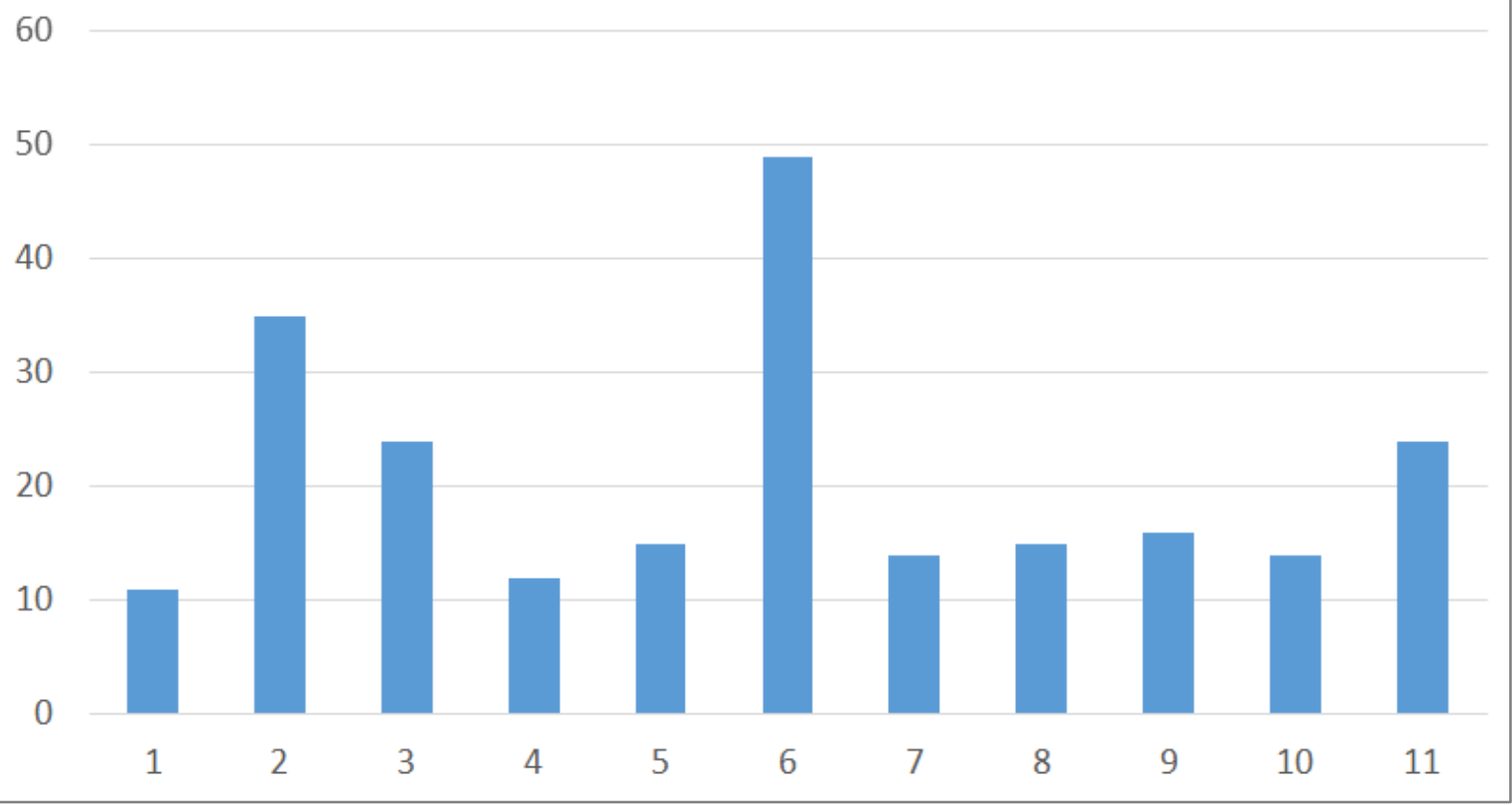

Figure 4. Mostly responded alternate responses

Table 10. Most common misconceptions aroused from the observation of learners' performances

\begin{tabular}{|c|c|c|c|c|}
\hline $\begin{array}{l}\text { Sl. } \\
\text { No. }\end{array}$ & $\begin{array}{c}\text { Source of Alternate } \\
\text { Concept (test item/No. of } \\
\text { alternate concept) }\end{array}$ & Type of Response & $\begin{array}{c}\% \\
\text { response }\end{array}$ & What is missing \\
\hline 1 & $1 / 4$ & $\begin{array}{l}\text { Periodic Table inform us about (a) Symbols } \\
\text { of elements \& (b) Structure of atoms of } \\
\text { elements }\end{array}$ & 11 & $\begin{array}{l}\text { Periodic table also provide with the } \\
\text { properties of elements. }\end{array}$ \\
\hline 2 & $2 / 3$ & $\begin{array}{l}\text { Atomic number determine position of } \\
\text { element in periodic table. }\end{array}$ & 35 & $\begin{array}{l}\text { Atomic number provide the } \\
\text { Structure and properties of elements. }\end{array}$ \\
\hline 3 & $2 / 4$ & $\begin{array}{l}\text { Atomic number determine structure \& } \\
\text { chemical properties of atoms. }\end{array}$ & 24 & $\begin{array}{l}\text { Atomic number determine the } \\
\text { position of elements in periodic } \\
\text { table. }\end{array}$ \\
\hline 4 & $3 / 1$ & Mainly non-metals & 12 & $\begin{array}{c}\text { No idea of position and properties of } \\
\text { elements. }\end{array}$ \\
\hline 5 & $3 / 3$ & Mainly metals & 15 & Missing hydrogen as non-metal \\
\hline 6 & $4 / 2$ & 18 groups and 7 periods & 49 & $\begin{array}{l}\text { Missing block idea for periodic } \\
\text { table. }\end{array}$ \\
\hline 7 & $4 / 3$ & $\begin{array}{c}\mathrm{S}, \mathrm{p}, \mathrm{d} \text {, and f blocks and } 7 \text { groups } \& 18 \\
\text { periods. }\end{array}$ & 14 & Missing idea of period and groups. \\
\hline 8 & $5 / 1$ & Inform about symbols of elements & 15 & $\begin{array}{l}\text { No idea of relation between } \\
\text { chemical properties and periodic } \\
\text { table. }\end{array}$ \\
\hline 9 & $7 / 1$ & Compounds & 16 & $\begin{array}{l}\text { Confusion that atoms of elements } \\
\text { have alphabetical symbols. }\end{array}$ \\
\hline 10 & $7 / 3$ & None & 14 & $\begin{array}{l}\text { No idea that alphabets are used to } \\
\text { represent elements. }\end{array}$ \\
\hline 11 & $8 / 2$ & Compounds are represented by symbols & 24 & $\begin{array}{l}\text { Confusing concepts. Missing that } \\
\text { elements are also represented by } \\
\text { symbols. }\end{array}$ \\
\hline
\end{tabular}




\section{Conclusion}

It is possible for students from different schools to perform differently in a particular area of chemistry, such as the Periodic Table. While some students do admirably and others struggle, when it comes to conceptual misunderstanding, students universally demonstrate their lack of confidence when it comes to the same topics. It is critical that attention be paid to the development of suitable cognitive abilities. When presenting elements to high school chemistry students, extra care must be used. A brief guideline is provided for classroom teachers while giving Atoms and Periodic Table classes.

1. Emphasis should be placed on the proper use of alphabetical symbols when referring to elements (metals and non-metals), atoms, and molecules (both element and compound). For elementary Hydrogen is written $\mathrm{H}_{2}$ but $\mathrm{C}_{2}$ is not written for elementary Carbon. Additionally, why do we not write $\mathrm{H}_{3}$ but merely $\mathrm{H}_{2}$ and so forth? What similarities exist between $\mathrm{O}_{2}$ and $\mathrm{CO}_{2}$ ?

2. Why is $\mathrm{H}_{2} \mathrm{O}$ written, but $\mathrm{HO}_{2}$ is not?

3. Emphasis should be placed on the relationship between the structure and properties of an element and its position in the periodic table.

4. When dealing with the contents of atoms and the periodic table, it is necessary to pay attention to the relationship between atomic number, atomic properties, atomic structure (particularly s, p, and $\mathrm{d}$ blocks), and position in the periodic table.

In order to instill $21^{\text {st }}$ century cognitive skills amongst students a six point guideline is suggested by the author for all chemistry educators.

They are:

\section{Attention}

Take note of the periodic table's position and attributes of atoms. Despite its presence in group one, $\mathrm{H}$ is a non-metal.

\section{Memorization}

Bear in mind the blocks and group relationships. Position of metals and non-metals in the periodic table. $\mathrm{H}$ is a group one non-metal.

\section{Perception}

Develop a distinct concept for writing symbols. Why do we write them and when do we write them?

\section{Mobility}

Mobility can be described as the capacity for social interaction. Obstacles to social growth result in a stumbling block to learning. As a result, group activities in chemistry courses are critical.

\section{Processing}

Processing ability enables a learner to move quickly and efficiently from one difficulty to the next. It is critical that learners receive appropriate guidance.

\section{Logic and Argumentation}

"Who, Which, Why, and What?" A line from our childhood rhyme can be answered only via the application of sound logic and thinking. Educators must foster this ability in students.

\section{Declaration of Ethics}

This study received no funding. The author also expresses his gratitude to Dr. Rankhumise MP, Senior lecturer, department of science, mathematics and business education for providing all strategic support during the course of the study.

\section{REFERENCES}

[1] Kivunja, C. Teaching Students to Learn and to Work Well with 21st Century Skills: Unpacking the Career and Life Skills Domain of the New Learning Paradigm. International Journal of Higher Education, vol. 4, no. 1, pp. 1-11, 2015.

[2] Zorlu, F.; \& Zorlu, Y. Investigation of The Relationship Between Preservice Science Teachers' 21st Century Skills and Science Learning Self-Efficacy Beliefs with Structural Equation Model. Journal of Turkish Science Education, vol. 18, no. 1, pp. 1-16, 2021. DOI no: 10.36681/tused.2021.49.

[3] Trilling, B., \& Fadel, C. $21^{\text {st }}$ Century skills: Learning for life in our times. John Wiley \& Sons, 2009.

[4] Eryılmaz, S., \& Uluyol, Ç. (2015). Evaluation of FATIH project in the consideration of 21st century skills. Gazi University Journal of Gazi Educational Faculty, vol. 35, no. 2, pp. 209-229, 2015.

[5] Hofstein, A.; \& Mamlok-Naaman, R. High-school Students' attitudes toward and interest in learning chemistry. Educación Química, vol. 22, no. 2, pp. 90-102, 2011.

[6] Niaz, M. \& Luiggi, M. Facilitating Conceptual change in Students' Understanding of the Periodic table. Springer, 2014. DOI: 10.1007/978-3-319-01086-1.

[7] Osman, K. Addressing Secondary School Students' Misconceptions about Simple Circuits Using the Learning Cycle Approach. In; Overcoming Students' Misconceptions in Science, Karpudewan, M.; Md. Zain, A.; and Chandrasegaran, A. (Eds), Springer. 2017, DOI: 10.1007/978-981-10-3437-4_12.

[8] Chowdhury, P.; Rankhumise, M. P.; Simelane-Mnisi, S.; \& Mafa-Theledi, O. N. Identifying High School Students' Alternate Concepts in Periodic Table, Conference proceedings of $12^{\text {th }}$ Annual International Conference of Education. Research and Innovation, 2019, pp. 9975. DOI:10.21125/iceri.2019.2445. 
[9] Schmidt, H. J.; Baumgärtner, T.; \& Eybe, H. Changing ideas about the Periodic Table of elements and students' alternative concepts of isotopes and allotropes. Journal of Research in Science Teaching, vol. 40, no. 3, pp. 257-277, 2003.

[10] Ben-Zvi, N.; \& Genut, S. Uses and limitations of scientific models: the Periodic Table as an inductive tool. International Journal of Science Education, vol. 20, pp. 351-360, 1998.

[11] Brito, A.; Rodríguez, M. A.; \& Niaz, M. A reconstruction of development of the Periodic Table based on history and philosophy of science and its implications for general chemistry textbooks. Journal of Research in Science Teaching, vol. 42, pp. 84-111, 1995.

[12] Scerri, E. R. The Periodic Table: its story and its significance. Oxford University Press, New York, 2007.

[13] Chowdhury, P. Preparing Modified Bonding Representations Inventory: Challenges and Solutions, Indonesian Journal of Educational Research and Review, vol. 4, no. 3, pp. 441-448, 2021.

[14] Luxford, C. J.; \& Bretz, S. L. Moving beyond definitions:
What student-generated models reveal about their understanding of covalent bonding and ionic bonding. Chemistry Education Research and Practice, vol. 14, pp. 214-222, 2013

[15] Luxford, C. J.; \& Bretz, S. L. Development of the Bonding Representations Inventory to Identify Student Misconceptions about Covalent and Ionic Bonding Representations. Journal of Chemical Education, vol. 91, pp. 312-320, 2014.

[16] Vrabec, M.; \& Prokŝa, M. Identifying Misconceptions Related to Chemical Bonding Concepts in the Slovak School System Using the Bonding Representations Inventory as a Diagnostic Tool. Journal of Chemical Education, vol. 93, no. 8, pp. 1364-1370, 2016. DOI: 10.1021/acs.jchemed.5b00953

[17] Taber, K. S.; \& Watts, M. Constructivism and concept learning in chemistry: Perspectives from a case study. Research in Education, vol. 58, pp. 10-20, 1997.

[18] Chowdhury, P. Make High school Teachers to Learn: How We Learn Better. Anuario Latino Americano De Educacion Quimicia 2015-2016, 2016, vol. xxix, No. xxxi, pp. 91-95. 